\title{
Article \\ Photo-Fenton Oxidation of Methyl Orange Dye Using South African Ilmenite Sands as a Catalyst
}

\author{
Alicia Levana Butt, John Kabangu Mpinga and Shepherd Masimba Tichapondwa * \\ Department of Chemical Engineering, Water Utilization and Environmental Engineering Division, \\ University of Pretoria, Pretoria 0002, South Africa; alicialbutt@gmail.com (A.L.B.); \\ johnmpingaka@gmail.com (J.K.M.) \\ * Correspondence: shepherd.tichapondwa@up.c.za; Tel.: +27-(012)-420-3741
}

check for

updates

Citation: Butt, A.L.; Mpinga, J.K.; Tichapondwa, S.M. Photo-Fenton Oxidation of Methyl Orange Dye Using South African Ilmenite Sands as a Catalyst. Catalysts 2021, 11, 1452. https://doi.org/10.3390/ catal11121452

Academic Editors: Paola Semeraro and Roberto Comparelli

Received: 21 October 2021

Accepted: 26 November 2021

Published: 29 November 2021

Publisher's Note: MDPI stays neutral with regard to jurisdictional claims in published maps and institutional affiliations.

Copyright: (c) 2021 by the authors. Licensee MDPI, Basel, Switzerland. This article is an open access article distributed under the terms and conditions of the Creative Commons Attribution (CC BY) license (https:// creativecommons.org/licenses/by/ $4.0 /)$.

\begin{abstract}
In this study, the viability of South African ilmenite sands as a catalyst in the photo-Fentonlike degradation of methyl orange (MO) dye was investigated. The mineralogy and other properties of the material were characterized. Complete decolorization occurred under acidic conditions $(\mathrm{pH}<4)$ in the presence of ilmenite and $\mathrm{H}_{2} \mathrm{O}_{2}$. Light irradiation accelerated the rate of reaction. Parameter optimization revealed that a $\mathrm{pH}$ of 2.5, UVB irradiation, $2 \mathrm{~g} / \mathrm{L}$ catalyst loading, and a hydrogen peroxide concentration of $1.0 \mathrm{mM}$ were required. Under these conditions, complete decolorization was observed after $45 \mathrm{~min}$. Degradation kinetics were best described by the pseudofirst order (PFO) model. Rate constants of 0.095 and $0.034 \mathrm{~min}^{-1}$ were obtained for 5 and $20 \mathrm{mg} / \mathrm{L}$ MO concentrations, respectively. A 37\% total organic carbon removal was observed after $60 \mathrm{~min}$. This suggests a stepwise MO degradation pathway with intermediate formation rather than complete mineralization. Although iron leaching was detected, the mineralogy of the catalyst recovered after the reaction was similar to the fresh catalyst.
\end{abstract}

Keywords: Fenton's reaction; AOPs; wastewater; degradation; textile dye

\section{Introduction}

The increased demand for clean, potable water coupled with diminishing access to clean water sources has resulted in a growing need for research into alternative water sources, with water reuse showing great potential [1,2]. Anthropogenic activities such as manufacturing and agricultural activities generate large volumes of effluents contaminated with aromatic organic compounds, which are classified as refractory or emerging pollutants. If left untreated, these compounds pose serious health threats as they possess known endocrine-disrupting and carcinogenic properties [3,4]. Conventional biological wastewater treatment processes are the most widely used in wastewater treatment [5]. However, these processes are incapable of degrading the recalcitrant priority and some emerging pollutants. As a result, tertiary water treatment processes such as adsorption [6] and membrane separation have been implemented to remediate these compounds to make the effluent suitable for reuse. While these technologies have been shown to be effective [7], they tend to generate secondary waste streams that require further treatment or specialized containment [7]. Advanced oxidation processes (AOPs) are a group of technologies that have emerged to eliminate these shortcomings due to their ability to break down and mineralize refractory organic compounds to benign carbon dioxide and water [8]. The principle behind AOPs is driven by the generation of highly oxidative free radicals that participate in redox chemical reactions, which drive the degradation process [9]. The Fenton reaction is one of the most effective AOPs; it uses soluble iron salts and hydrogen peroxide to generate highly reactive hydroxyl radicals. Although commonly used, the Fenton reaction is problematic as it introduces large quantities of iron into solution and generates secondary metal-containing sludge [9-11]. Resultantly, modifications to the process have been implemented; chief amongst these is the use of alternative sources of 
iron [12,13]. Additionally, introducing light to the reactor setup to obtain the so-called photo-Fenton reaction reportedly allows for faster catalyst regeneration [14,15]. This results in a superior performance compared to the classical Fenton's reagent [16].

Catalytic wet peroxide oxidation (CWPO) is one of the AOPs developed to overcome the problems associated with the classical Fenton reaction $[9,17]$. This process uses a solid metal-bearing catalyst instead of a soluble metal salt to avoid excessive metal leaching and sludge formation [18]. Current research in CWPO focuses on identifying and developing efficient, cost-effective catalysts for use in systems utilized to degrade a range of pollutants [19]. The catalysts used are generally classified as natural or synthetic, with synthetics comprised of a large group of different types. Numerous catalysts and composite materials have been developed with varying levels of efficiency reported [18]. However, it is generally accepted that the complicated synthesis methods and expensive raw materials make them economically unviable $[19,20]$. Emerging research has therefore focused on identifying naturally occurring minerals that can be used as alternative catalysts [21-23].

Ilmenite $\left(\mathrm{FeTiO}_{3}\right)$ is one such minerals that has shown promise as a catalyst for AOPs. The presence of redox-active Fe elements in the ilmenite structure makes it suitable for Fenton-like processes, while the presence of $\mathrm{TiO}_{2}$ allows for potential photocatalytic activity [21]. These researchers obtained a significant degradation efficiency and TOC removal for phenol and real hospital wastewater [24,25]. Additionally, Pataquiva-Mateus et al. [26] conducted a study using three Colombian ilmenites from different locations as catalysts for the decolorization of the azo dye, namely Orange II, in the Fenton's reaction. The study found that the catalyst with the most significant percentage of iron (56.7\%) led to the fastest decolorization rate, with complete decolorization achieved following $9 \mathrm{~h}$ of reaction time.

It is worth noting that while naturally occurring minerals have been proven to be effective and low-cost catalysts, their mineralogy will vary with location. This ultimately influences the chemical and physical properties of the catalyst, and varying efficiencies might be observed for ores with the same major compounds. This study is therefore aimed at determining the viability of naturally occurring South African ilmenite as a catalyst in the CWPO process using methyl orange as a model compound. The optimum reaction parameters are investigated and the reaction mechanism is elucidated.

\section{Results}

\subsection{Catalyst Characterization}

The mineralogy of the catalyst was determined through XRD analysis; the results obtained are presented in Figure 1. The most pronounced peaks were observed at $2 \theta$ values of $27.8,38.1,41.2$, and 62.5 . These were attributed to the presence of ilmenite which accounted for $83.53 \%$ of the composition. Hematite (14.99\%) and trace amounts of rutile $(1.2 \%)$ were also detected. Hematite has been reported to be an effective catalyst in Fentontype reactions and positively contributes to the performance of ilmenite [9]. Titanium oxide is one of the most widely used catalysts in photocatalysis due to its ability to generate highly reactive free radicals following electron/hole pair separation under light irradiation [9]. For this study, it is postulated that the influence of $\mathrm{TiO}_{2}$ will be negligible since it is present in trace amounts. Additionally, it has been reported that the rutile phase detected had a lower efficacy compared to anatase, a polymorph of $\mathrm{TiO}_{2}$ [27]. An XRF analysis revealed the elemental distribution to be $\mathrm{Fe}(34.6 \mathrm{wt} . \%)$, $\mathrm{Ti}(32.3 \mathrm{wt} . \%)$, and oxygen (28.73 wt.\%), with trace amounts of $\mathrm{Mn}, \mathrm{Mg}, \mathrm{Al}$, and $\mathrm{V}$, respectively. 


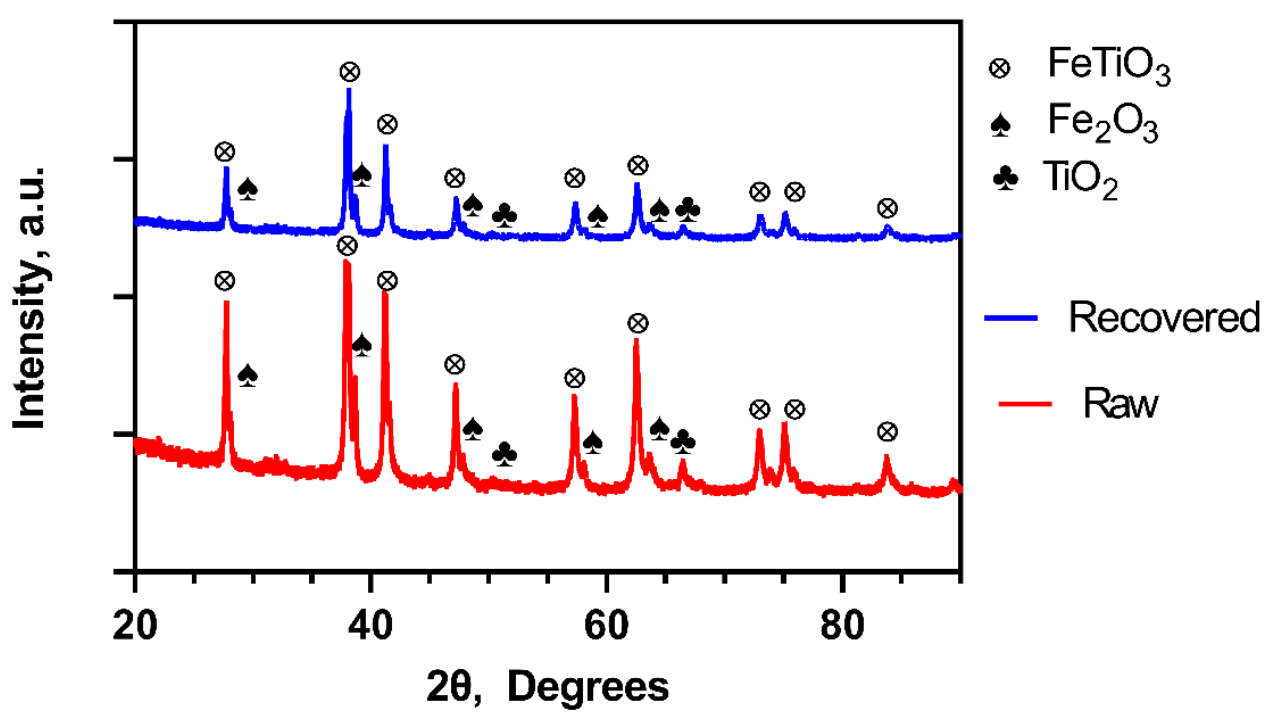

Figure 1. XRD spectra and the associated mineralogy of the catalyst before (raw) and after the (recovered) reaction.

It should be noted that the theoretical weight percentages of elements in pure ilmenite are $36.8 \% \mathrm{Fe}, 31.6 \% \mathrm{Ti}$, and $31.6 \% \mathrm{O}$. However, since the present sample is natural and not purified, variations are expected. Table 1 summarizes characterization results reported by other researchers. The majority of the studies had a higher $\mathrm{TiO}_{2}$ concentration and a minimal amount of hematite.

Table 1. Comparison of the ilmenite catalyst used in this study compared to the ilmenite used in other studies.

\begin{tabular}{|c|c|c|c|c|c|c|}
\hline \multirow{2}{*}{ Study } & \multicolumn{3}{|c|}{ XRD (\%) } & \multicolumn{2}{|c|}{ XRF (\%) } & \multirow{2}{*}{$\begin{array}{c}\text { BET } \\
\left(\mathrm{m}^{2} / \mathrm{g}\right)\end{array}$} \\
\hline & $\mathrm{FeTiO}_{3}$ & $\mathrm{Fe}_{2} \mathrm{O}_{3}$ & $\mathrm{TiO}_{2}$ & $\mathrm{Fe}$ & $\mathbf{T i}$ & \\
\hline Present study (before reaction) & 83.53 & 14.99 & 1.2 & 34.60 & 32.30 & 10.42 \\
\hline Present study (recovered catalyst after reaction) & 82.43 & 16.08 & 1.49 & - & - & - \\
\hline García-Muñoz et al. [21] & 85 & - & 15 & 36 & 37 & 6 \\
\hline Canas-Martinez et al. [28] & 69.50 & 2.81 & 4.18 & $\mathrm{NA}^{*}$ & NA * & $\mathrm{NA}^{*}$ \\
\hline Silveira et al. [29] & 85 & - & 15 & 36 & 37 & 6 \\
\hline Munoz et al. [22] & $\mathrm{NA}^{*}$ & $\mathrm{NA}^{*}$ & $\mathrm{NA}^{*}$ & 36.2 & 37.0 & 4 \\
\hline
\end{tabular}

* Information not reported in the reference.

Figure 2 shows the morphology of the catalyst used in the study. The larger particles had an irregular angular morphology while the smaller particles had a near-spherical shape with a high degree of agglomeration. The primary size of the particles in the agglomerates was in the nano-range. It was postulated that these particles gave rise to the higher BET surface area $\left(10.42 \mathrm{~m}^{2} / \mathrm{g}\right)$ recorded in the present study compared to the values reported in literature (Table 1). EDS images (Figure S1) confirmed a relatively even distribution of titanium and iron throughout the material. The scattered silicon clusters were attributed to amorphous $\mathrm{SiO}_{2}$ since no crystalline quarts were detected in the XRD analysis.

\subsection{Control Experiments}

The effect of various process parameters on the decolorization of methyl orange dye over time is presented in Figure 3. The time -30 to 0 min represents the experiment run in the absence of light (in the dark). Minimal decolorization was observed in the presence of ilmenite and $\mathrm{H}_{2} \mathrm{O}_{2}$ alone. This is expected since the experiments were conducted at low $\mathrm{pH}$ values, which are known to enhance the stability of $\mathrm{H}_{2} \mathrm{O}_{2}$ [30]. However, the catalyst and $\mathrm{H}_{2} \mathrm{O}_{2}$ (dark) had a combined result in $84 \%$ degradation after $120 \mathrm{~min}$. It should be noted that only ilmenite was present in the first $30 \mathrm{~min}$ from -30 to $0 \mathrm{~min}$ and no degradation 
was observed. Upon the introduction of $\mathrm{H}_{2} \mathrm{O}_{2}$, a noticeable decolorization was recorded. This confirms that the system behaves similarly to the Fenton's reaction, where a source of iron and $\mathrm{H}_{2} \mathrm{O}_{2}$ is required to form the highly reactive hydroxyl $(\bullet \mathrm{OH})$ free radicals.

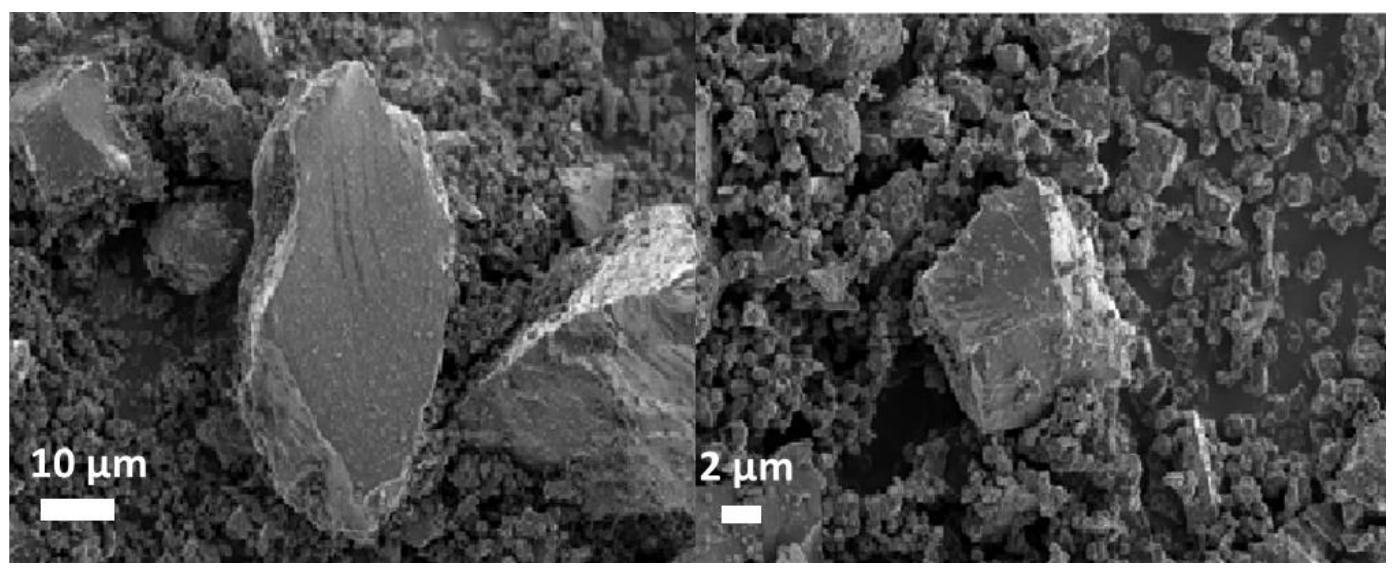

Figure 2. SEM images of the raw ilmenite catalyst at various magnifications.

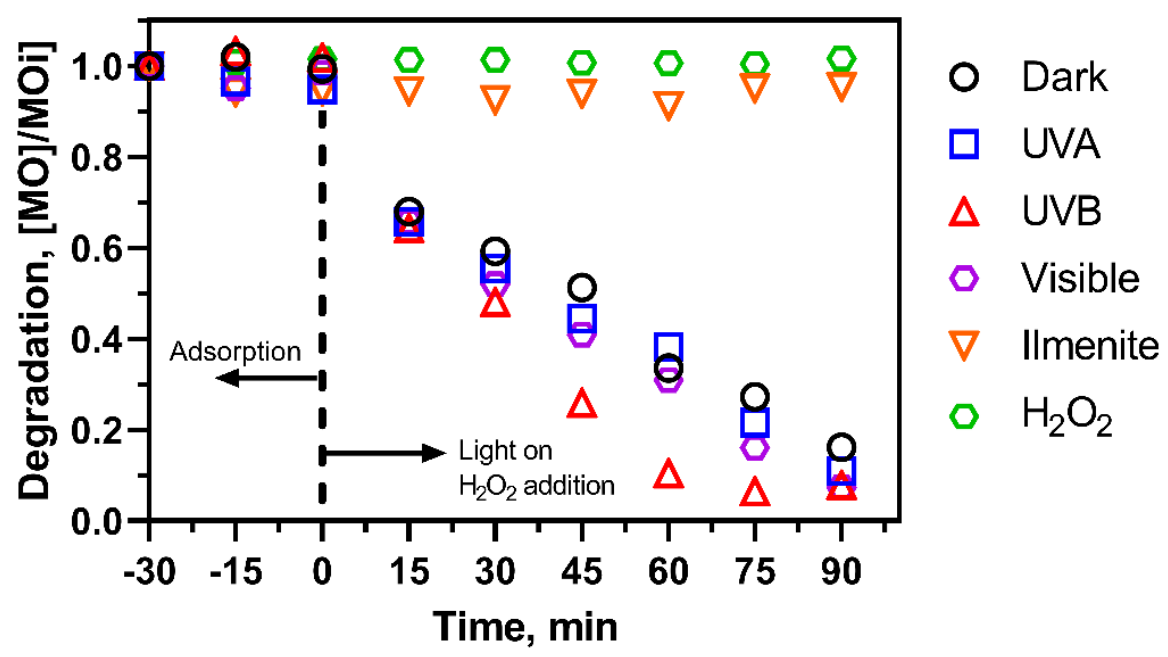

Figure 3. The degradation of methyl orange under the presence and/or absence of various parameters. Operating conditions: $(\mathrm{MO})=10 \mathrm{mg} / \mathrm{L},\left(\mathrm{H}_{2} \mathrm{O}_{2}\right)=2.5 \mathrm{mM}$, (ilmenite) $=1000 \mathrm{mg} / \mathrm{L}, \mathrm{pH}=3$, and temperature $= \pm 20^{\circ} \mathrm{C}$.

This is because the addition of UV irradiation creates a second pathway for radical generation, as shown in reactions 1 and 2 [16]:

$$
\begin{gathered}
\mathrm{Fe}^{2+}+\mathrm{H}_{2} \mathrm{O}_{2} \rightarrow \mathrm{Fe}^{3+}+\bullet \mathrm{OH}+\mathrm{OH}^{-} \quad \text { (Fenton reaction) } \\
\mathrm{Fe}(\mathrm{OH})^{2+} \stackrel{\text { hv }}{\rightarrow} \mathrm{Fe}^{2+}+\bullet \mathrm{OH} \quad \text { (photo-Fenton reaction) }
\end{gathered}
$$

This second pathway leads to efficient cycling between $\mathrm{Fe}^{2+}$ and $\mathrm{Fe}^{3+}$; here, the $\mathrm{Fe}^{3+}$ generated through the primary Fenton reaction is further reduced by the energy of the photons supplied through irradiation. It has long been observed that iron undergoes this type of cycling when exposed to light, particularly in natural waters with the photo-oxidation of dissolved organic matter [31]. Further research has shown that light is a driving force in the iron redox cycle in aquatic environments where it is able to reduce $\mathrm{Fe}^{3+}$ to $\mathrm{Fe}^{2+}$ by direct interaction with organic ligands or photochemically produced superoxide $[15,16,31]$.

In this study, the effect of various irradiation sources on the rate of degradation was investigated (Figure 3). UVA and visible light irradiation showed comparable degradation 
rates to the dark experiments; however, UVB irradiation resulted in a faster degradation. This is supported by literature which states that UVB irradiation is the most effective for $\mathrm{Fe}^{3+}$ photoreduction, thus increasing the amount of $\mathrm{Fe}^{2+}$ in the system compared to other irradiation wavelengths [32-34]. A study conducted by Eskandarian et al. [35] on the degradation of pharmaceuticals using $\mathrm{TiO}_{2}$ in photocatalysis examined the effect of different wavelengths on degradation efficiency. They found that as the irradiation wavelength increased, photo energy decreased and thus degradation rates also decreased. It is thought that this observation might explain why UVB irradiation had the fastest degradation rate compared to the UVA and visible light wavelengths in the present study. In addition, UVB irradiation has been shown to produce higher concentrations of $\mathrm{Fe}^{2+}$ than UVA irradiation [36].

\subsection{Effect of $p H$}

The $\mathrm{pH}$ plays a critical role in the classic Fenton's reaction. Several studies have reported the optimum $\mathrm{pH}$ to be in a narrow range between 2 and $3[14,16]$. Figure $4 \mathrm{a}$ reports the $\mathrm{MO}$ degradation at various $\mathrm{pH}$ under UVB irradiation. Complete decolorization was observed after $75 \mathrm{~min}$ for the $\mathrm{pH}$ levels 2.0 and 2.5, and after $90 \mathrm{~min}$ for $\mathrm{pH}$ 3.0. Virtually no degradation was recorded at $\mathrm{pH} 5$. Complementary studies to determine whether the $\mathrm{pH}$ influences the availability of Fe and ultimately the extent of the reaction were also conducted. These results are presented in Figure $4 \mathrm{~b}$. The Fe available in the solution increased with decreasing initial $\mathrm{pH}$. A maximum iron concentration of $1.88 \mathrm{mg} / \mathrm{L}$ for $\mathrm{pH} 2$ and $0.55 \mathrm{mg} / \mathrm{L}$ for $\mathrm{pH} 3$ was determined after $120 \mathrm{~min}$ of contact time. It is noteworthy that at $\mathrm{pH} 5$, no iron leached was detected. This suggests that the degradation reaction proceeded as a homogeneous Fenton-type reaction rather than a heterogeneous reaction [33] since Fe had to leach from the catalyst before the degradation process. Several studies have reported that homogeneous Fenton-type reactions are associated with the sludge formation and deactivation of the solid catalysts since continuous leaching results in the destruction of the catalyst $[15,37]$. However, in this study, no noticeable change in the crystal structure was observed after the reaction (Figure 1).

Optimum degradation occurred at $\mathrm{pH} 2.5$; this was attributed to the combined behavior of $\mathrm{Fe}$ and $\mathrm{H}_{2} \mathrm{O}_{2}$ at different $\mathrm{pH}$ values. At $\mathrm{pH}$ values above 3, the reduced iron $\left(\mathrm{Fe}^{2+}\right)$ can potentially re-oxidize and precipitate, resulting in decreased $\bullet \mathrm{OH}$ generation $[38,39]$. Additionally, it has been reported that when the solution $\mathrm{pH}$ is below 2.5, the scavenging effect of the $\bullet \mathrm{OH}$ radicals increases due to the excess $\mathrm{H}^{+}$ions generated [19]. García-Muñoz et al. [40] showed that the use of ilmenite in the CWPO process could work efficiently at a circumneutral $\mathrm{pH}$; this was attributed to the high percentage of rutile in the ilmenite sample. The authors suggest that different mechanisms drive $\mathrm{H}_{2} \mathrm{O}_{2}$ decomposition at different $\mathrm{pH}$ levels. They posit that under a circumneutral $\mathrm{pH}$, decomposition is mainly driven by the generation of electron/hole pairs that can be attributed to the $\mathrm{TiO}_{2}$ content. In this study, it is unlikely that this mechanism was dominant given the low quantities of $\mathrm{TiO}_{2}$ present in the catalyst (Table 2).

Table 2. Kinetic parameters obtained after fitting the PFO and PSO kinetic models to the experimental data.

\begin{tabular}{ccccc}
\hline \multirow{2}{*}{ Concentration } & \multicolumn{2}{c}{ First Order } & \multicolumn{2}{c}{ Second Order } \\
\cline { 2 - 5 } & $\kappa\left(\mathbf{m i n}^{-1}\right)$ & $\mathbf{R}^{\mathbf{2}}$ & $\kappa\left(\mathbf{L} /\left(\mathbf{m o l} \cdot \mathbf{m i n}^{-\mathbf{1}}\right)\right.$ & $\mathbf{R}^{\mathbf{2}}$ \\
\hline $5 \mathrm{mg} / \mathrm{L}$ & 0.09538 & 0.996 & 0.06485 & 0.9957 \\
$10 \mathrm{mg} / \mathrm{L}$ & 0.07856 & 0.9985 & 0.02120 & 0.9828 \\
$20 \mathrm{mg} / \mathrm{L}$ & 0.03429 & 0.9886 & 0.003882 & 0.9476 \\
\hline
\end{tabular}



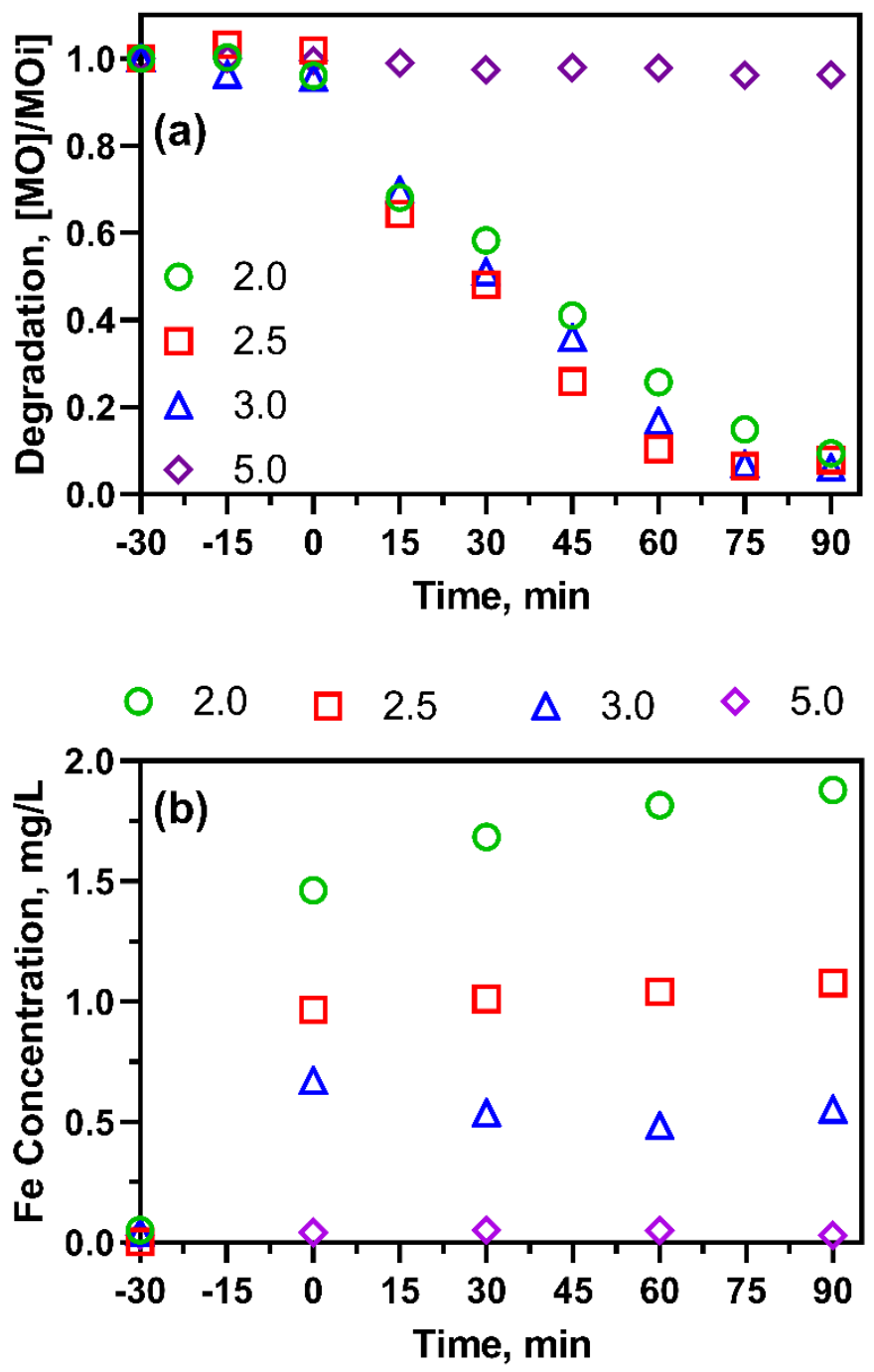

Figure 4. (a) Degradation of methyl orange at different $\mathrm{pH}$ levels under the influence of the UVB irradiation (b) leaching of $\mathrm{Fe}$ into the solution at different $\mathrm{pH}$ values. Operating conditions: $(\mathrm{MO})=10 \mathrm{mg} / \mathrm{L},\left(\mathrm{H}_{2} \mathrm{O}_{2}\right)=2.5 \mathrm{mM}$, (ilmenite) $=1000 \mathrm{mg} / \mathrm{L}$, temperature $= \pm 20^{\circ} \mathrm{C}$, and irradiation $=\operatorname{UVB}(\lambda=310-350 \mathrm{~nm})$.

The iron Pourbaix diagram reveals that speciation strongly depends on solution $\mathrm{pH}[38,39]$. At $\mathrm{pH}$ values below 9, $\mathrm{Fe}^{2+}$ is the dominant species, while below $\mathrm{pH} 4, \mathrm{Fe}^{3+}$ dominates. The presence of both Fe species is needed for the cycling of iron in the system, which increases the efficacy of the reaction. Therefore, the $\mathrm{pH}$ and irradiation source play a large role in the efficient cycling of iron in the photo-Fenton system [16].

The main reaction mechanism was therefore postulated to be similar to the classic Fenton reagent [41]. Firstly, $\mathrm{Fe}^{2+}$ enters the solution as a result of dissolution from the catalyst surface at low $\mathrm{pH}$. Thereafter, the dissolved Fe ions react with $\mathrm{H}_{2} \mathrm{O}_{2}$ to produce $\mathrm{Fe}^{3+}, \mathrm{OH}^{-}$, and a $\bullet \mathrm{OH}$ radical according to reaction 3 .

$$
\mathrm{Fe}^{2+}{ }_{(\mathrm{aq})}+\mathrm{H}_{2} \mathrm{O}_{2(\mathrm{aq})} \rightarrow \mathrm{Fe}^{3+}{ }_{(\mathrm{aq})}+\bullet \mathrm{OH}_{(\mathrm{aq})}+\mathrm{OH}^{-}{ }_{(\mathrm{aq})}
$$

The generated $\bullet \mathrm{OH}$ radical reacts with the methyl orange compound, breaking down the azo dye bonds and likely producing short-chain organic acids, some of which will be mineralized to $\mathrm{CO}_{2}$ and water as they are exposed to more hydroxyl free radicals (reaction 4).

$$
\mathrm{C}_{14} \mathrm{H}_{14} \mathrm{~N}_{3} \mathrm{NaS}_{(\mathrm{aq})}+\bullet \mathrm{OH}\left(\text { aq) } \rightarrow(\text { Short Chain Organic Acids })+\mathrm{H}_{2} \mathrm{O}+\mathrm{CO}_{2}\right.
$$


The generated $\mathrm{Fe}^{3+}$ in solution is reduced by the $\mathrm{OH}^{-}$to generate more $\mathrm{Fe}^{2+}$ and another $\bullet \mathrm{OH}$ radical according to reaction 5 below.

$$
\mathrm{Fe}^{3+}{ }_{(\mathrm{aq})}+\mathrm{OH}^{-}{ }_{(\mathrm{aq})} \rightarrow \mathrm{Fe}^{2+}{ }_{(\mathrm{aq})}+\bullet \mathrm{OH}_{(\mathrm{aq})}
$$

The proposed reaction and Fe cycling will continue until the depletion of $\mathrm{H}_{2} \mathrm{O}_{2}$ in the system. The free radicals react with the organic molecules present through three main mechanisms, namely demethylation, methylation, and hydroxylation [42,43].

Although some iron leaching does occur, it is evident from the XRD analysis (Figure 1) that negligible changes in mineral composition occur to the catalyst. Therefore, it is proposed that the reaction begins on the surface and continues in the solution once enough iron has leached. However, it is also noted through the iron leaching data that minimal quantities of iron are present in the solution. The reaction mechanism is more comparable to the classical homogeneous Fenton's reaction rather than the heterogeneous reaction [36].

\subsection{Effect of Catalyst Loading}

The effect of catalyst loading on the MO degradation efficiency was investigated and it was established that degradation increased with increasing catalyst loading (Figure 5a). Optimum degradation occurred at a loading of $2000 \mathrm{mg} / \mathrm{L}$; beyond this loading, no appreciable increase was observed. Figure $5 \mathrm{~b}$ indicates that the amount of iron leached into the solution increased with an increase in catalyst loading. Dissolved iron concentrations of 0.85 and $3.0 \mathrm{mg} / \mathrm{L}$ were recorded after $30 \mathrm{~min}$ of contact time for 500 and $2500 \mathrm{mg} / \mathrm{L}$ catalyst loadings, respectively. This observation was attributed to the simple increase in the amount of iron. However, an analysis of the ratio of leached iron compared to the theoretical iron available in the catalyst had an inverse relationship, where $0.49 \%$ iron was leached from $500 \mathrm{mg} / \mathrm{L}$ catalyst loading compared to $0.35 \%$ for the $2500 \mathrm{mg} / \mathrm{L}$ loading. Interestingly, the $2000 \mathrm{mg} / \mathrm{L}$ loading, which presented the fastest degradation rate, had $2.5 \mathrm{mg} / \mathrm{L}$ Fe in the solution, which corresponds to $0.36 \%$. This implies that a higher concentration of $\mathrm{Fe}^{2+}$ leached into the solution does not necessarily promote the degradation reaction; rather, it was postulated that there is a maximum level of $\mathrm{Fe}^{2+}$ in the solution that can react with $\mathrm{H}_{2} \mathrm{O}_{2}$ to generate $\bullet \mathrm{OH}$ radicals.

Figure 5 shows that while it took $90 \mathrm{~min}$ to achieve a maximum degradation from the onset of the run, maximum iron leaching occurred in the first $30 \mathrm{~min}$, after which the concentration remained constant. Further tests with shorter sampling times were conducted to determine the Fe leaching kinetics (Figure $5 \mathrm{c}$ ). The kinetics were best described by the pseudo-second order (PSO) model, which had an $\mathrm{R}^{2}$ value of 0.992 and a rate constant of 0.264 g. $\mathrm{mg}^{-1} \mathrm{~min}^{-1}$ compared to the $\mathrm{R}^{2}$ of 0.979 and rate constant of $0.78 \mathrm{~min}^{-1}$ for the pseudo-first order (PFO) model. The $95 \%$ prediction intervals are also presented in the shaded area. A narrower band observed in the PSO model signifies better probability for future observations and it can confidently be used for further work.

\subsection{Effect of $\mathrm{H}_{2} \mathrm{O}_{2}$ Concentration}

Hydrogen peroxide is an important reagent in the Fenton's reaction as it provides the reactive $\bullet \mathrm{OH}$ free radicals responsible for initiating the degradation reaction. The effect of $\mathrm{H}_{2} \mathrm{O}_{2}$ concentrations on the degradation of methyl orange is shown in Figure 6. The complete mineralization of $\mathrm{MO}$ occurs according to reaction 6. Based on this reaction, the $10 \mathrm{mg} / \mathrm{L} \mathrm{MO}$ concentration used in Figure 6 required $1.31 \mathrm{mM}$ of $\mathrm{H}_{2} \mathrm{O}_{2}$ at the stoichiometric ratio.

$$
\mathrm{C}_{14} \mathrm{H}_{14} \mathrm{~N}_{3} \mathrm{O}_{3} \mathrm{SNa}+43 \mathrm{H}_{2} \mathrm{O}_{2} \rightarrow 14 \mathrm{CO}_{2}+3 \mathrm{HNO}_{3}+\mathrm{NaHSO}_{4}+48 \mathrm{H}_{2} \mathrm{O}
$$




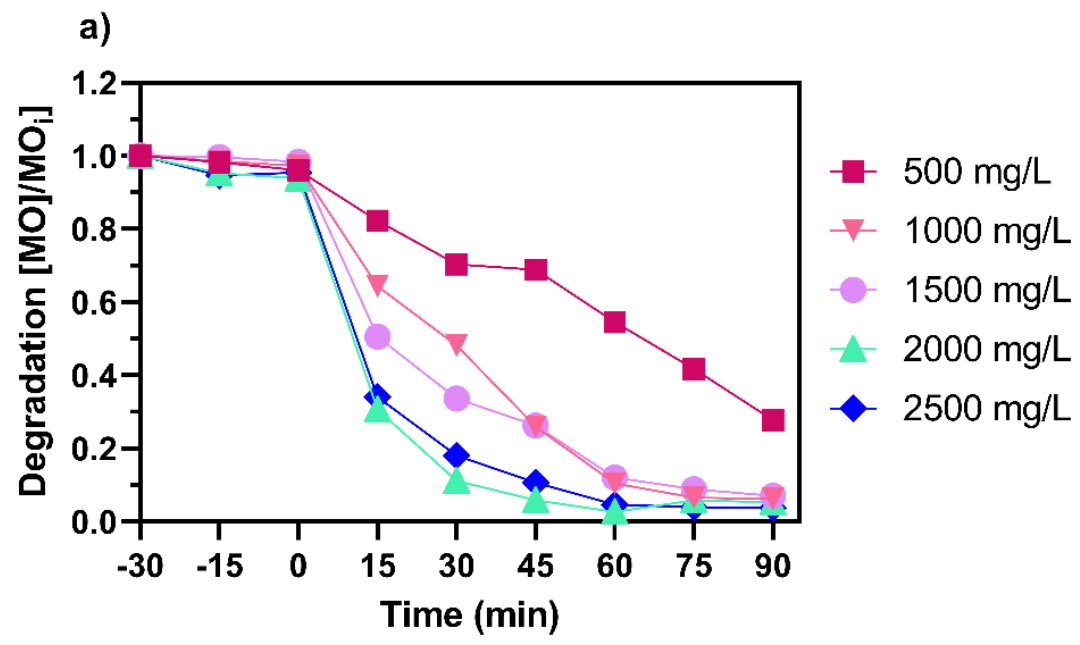

b)
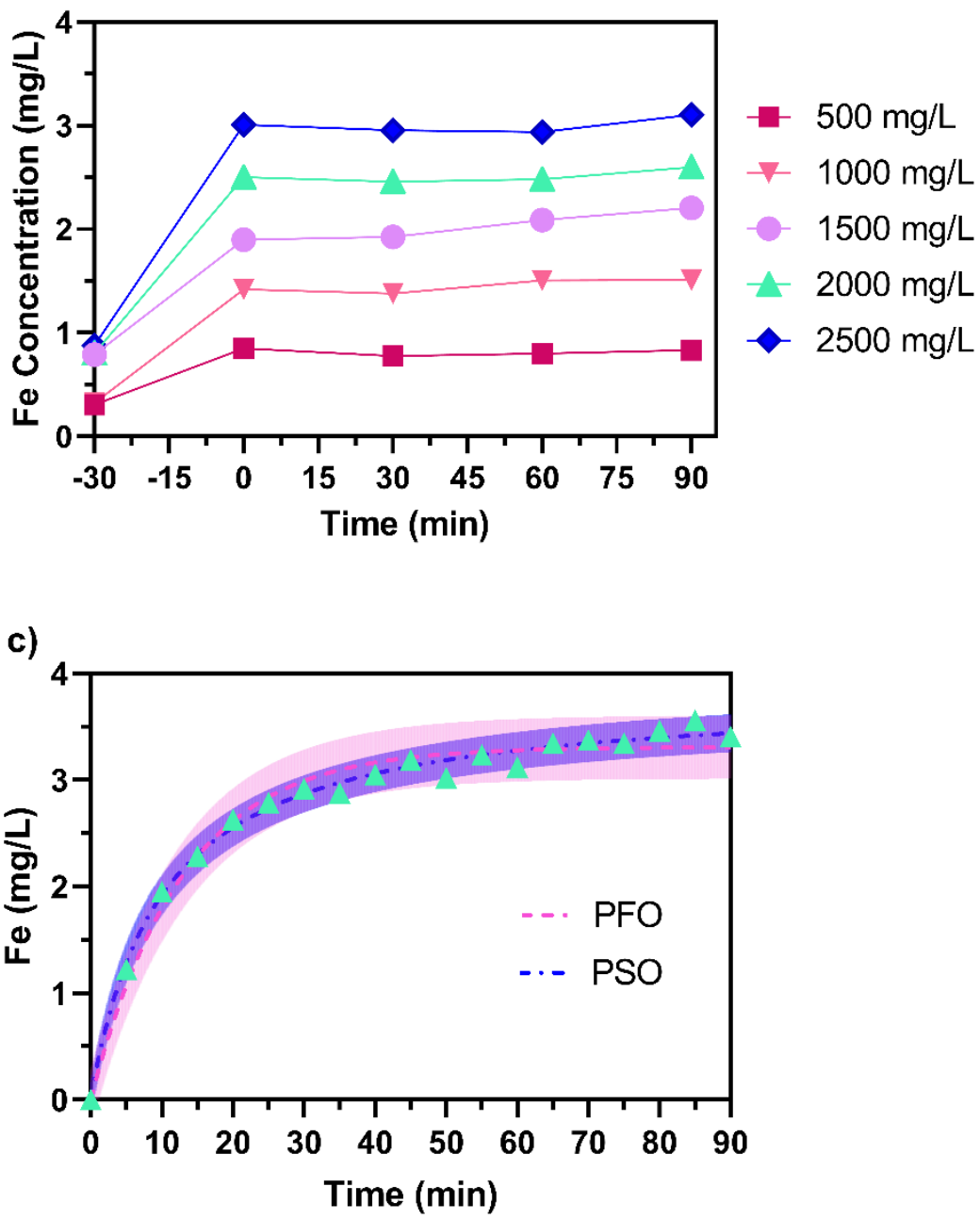

Figure 5. (a) Degradation of methyl orange at various catalyst loadings. (b) Iron leaching at various catalysts loadings. (c) Leaching kinetics at a $2000 \mathrm{mg} / \mathrm{L}$ loading. Operating conditions: $(\mathrm{MO})=10 \mathrm{mg} / \mathrm{L},\left(\mathrm{H}_{2} \mathrm{O}_{2}\right)=2.5 \mathrm{mM}, \mathrm{pH}=2.5$, irradiation = UVB $(\lambda=310 \mathrm{~nm}-350 \mathrm{~nm})$, and temperature $= \pm 20^{\circ} \mathrm{C}$. 


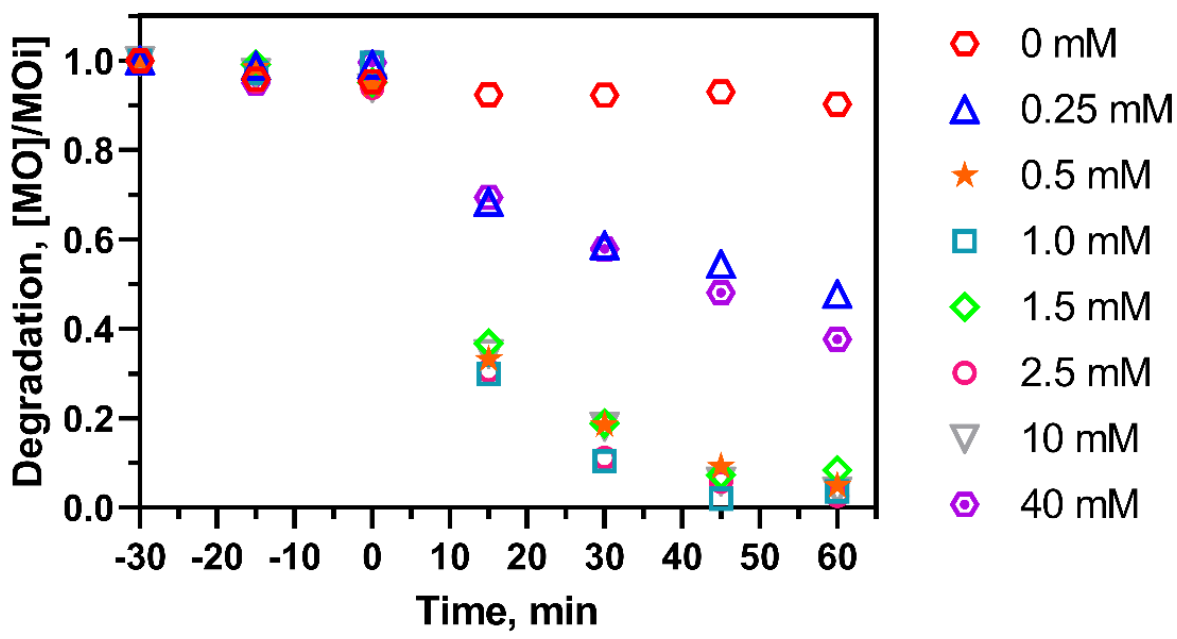

Figure 6. Effect of $\mathrm{H}_{2} \mathrm{O}_{2}$ concentration on methyl orange degradation. Operating conditions: $(\mathrm{MO})=10 \mathrm{mg} / \mathrm{L},($ ilmenite $]=2000 \mathrm{mg} / \mathrm{L}, \mathrm{pH}=2.5$, irradiation $=\mathrm{UVB}(\lambda=310 \mathrm{~nm}-350 \mathrm{~nm})$, and temperature $= \pm 20^{\circ} \mathrm{C}$.

Therefore, the concentrations of $0.25,0.5$, and $1 \mathrm{mM}$ in Figure 6 were below the stoichiometric amount required for complete breakdown of MO. Nevertheless, for the last two concentrations, complete decolorization of the $\mathrm{MO}$ was achieved. It should be noted that the amount of $\mathrm{H}_{2} \mathrm{O}_{2}$ required for the decolorization of $\mathrm{MO}$ with intermediate formation is lower than the stoichiometric amount required for the complete breakdown of the primary MO structure. When the stoichiometric amount was exceeded, i.e., at 1.5, 2.5, and even $10 \mathrm{mM}$, complete decolorization was also achieved. However, when the amount of $\mathrm{H}_{2} \mathrm{O}_{2}$ was too high, at $40 \mathrm{mM}$, i.e., about 30 times the stoichiometric amount, the catalytic activity dropped and only $60 \%$ of the $\mathrm{MO}$ was decolorized.

Excess $\mathrm{H}_{2} \mathrm{O}_{2}$ can lead to an increase in the scavenging effect by $\mathrm{H}_{2} \mathrm{O}_{2}$ on $\bullet \mathrm{OH}$ radicals, which can inhibit the reaction by producing weaker oxidizing radicals [19]. The scavenging effect of excess $\mathrm{H}_{2} \mathrm{O}_{2}$ is summarized in reaction 7 [44].

$$
\mathrm{H}_{2} \mathrm{O}_{2}+\bullet \mathrm{OH} \rightarrow \mathrm{H}_{2} \mathrm{O}+\bullet \mathrm{O}_{2} \mathrm{H}
$$

The resulting hydroperoxyl radical $\left(\bullet \mathrm{O}_{2} \mathrm{H}\right)$ has a lower redox potential $(1.7 \mathrm{~V})$ than the hydroxyl radical $(\bullet \mathrm{OH})$ which has a redox potential of $2.7 \mathrm{~V}[45,46]$. Therefore, these radicals have a lower oxidizing capacity and thus can decrease the rate of degradation [46].

\subsection{Effect of Initial MO Concentration}

The rate of methyl orange degradation was shown to be directly dependent on the initial concentration (Figure 7). A two-fold increase in the MO concentration from 5 to $10 \mathrm{mg} / \mathrm{L}$ did not show an appreciable change in the degradation rate; however, doubling the concentration to $20 \mathrm{mg} / \mathrm{L}$ slowed down the reaction significantly. This observation is most likely due to a variation in the pollutant to $\mathrm{H}_{2} \mathrm{O}_{2}$ stoichiometric ratio; at higher pollutant concentrations, the system became $\mathrm{H}_{2} \mathrm{O}_{2}$-deficient. In the present study, the initial concentration of the $\mathrm{H}_{2} \mathrm{O}_{2}$ was kept constant, resulting in $\mathrm{MO}$ to $\mathrm{H}_{2} \mathrm{O}_{2}$ ratios of 67,33 , and 16 for the 5,10 , and $20 \mathrm{mg} / \mathrm{L}$ amounts, respectively. Surprisingly, even though the rate of decolorization of the $20 \mathrm{mg} / \mathrm{L}$ MO solution was slow, near-complete degradation was still achieved after $60 \mathrm{~min}$. Other studies reported that the initial pollutant concentration did not affect the efficiency of the system when a stoichiometric amount of $\mathrm{H}_{2} \mathrm{O}_{2}$ was added in accordance with the initial organic load [18]. 


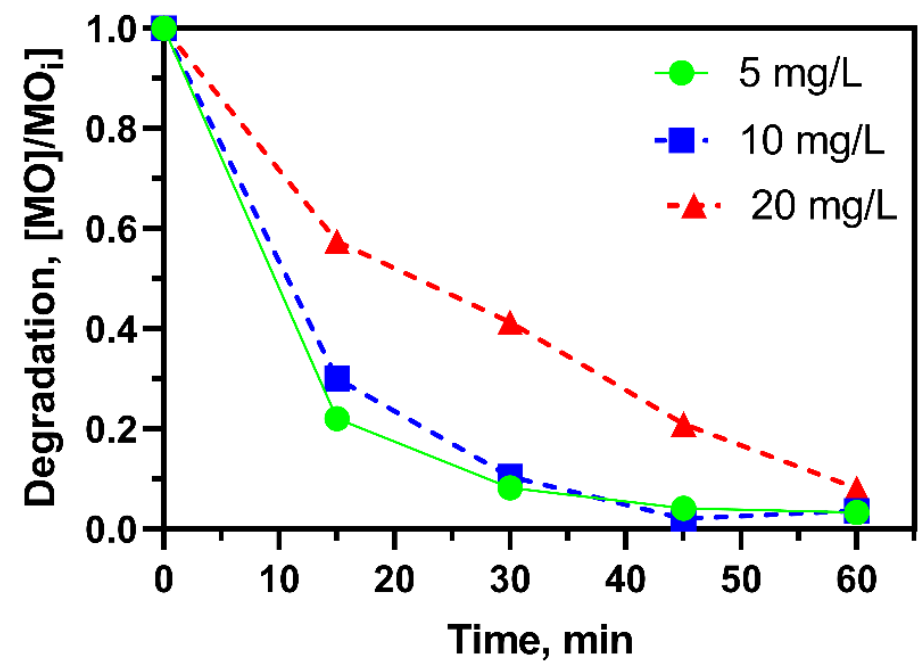

Figure 7. The degradation of methyl orange overtime at different initial concentrations. Operating conditions: (ilmenite $)=2000 \mathrm{mg} / \mathrm{L},\left(\mathrm{H}_{2} \mathrm{O}_{2}\right)=1.0 \mathrm{mM}, \mathrm{pH}=2.5$, irradiation $=\mathrm{UVB}(\lambda=310 \mathrm{~nm}-350 \mathrm{~nm})$, and temperature $= \pm 20^{\circ} \mathrm{C}$.

In order to further analyze the degradation kinetics at various initial MO concentrations, the experimental data were fit to several commonly used kinetic models. It is widely acknowledged that the Fenton's reaction mechanism is complex as it consists of numerous parallel and serial reactions involving different molecular and radical species [47]. Due to this complexity, performing a detailed kinetic analysis is challenging even for the model wastewaters, where most of the organic compounds present in the reaction mixture are known. Therefore, the data was fit to the pseudo-first order (PFO) and pseudosecond order (PSO) kinetic models. The analytical form of the equations is shown in Equations (8) and (9), respectively.

$$
\begin{gathered}
C=C_{0} e^{-k t} \\
C=\frac{C_{0}}{1+k C_{0} t}
\end{gathered}
$$

The fits for the two models at varying concentrations are shown graphically in Figure 8. The shaded areas in the figure show the $95 \%$ prediction bands for the respective fits. These bands represent the areas with a 95\% probability of future observations [48]. Table 2 summarizes the non-linear kinetic parameter fits for the models. Relatively good fits were obtained for the PFO model, with $\mathrm{R}^{2}$ values of 0.996 and 0.9886 for the initial concentration 5 and $20 \mathrm{mg} / \mathrm{L}$, respectively, while the PSO model had $\mathrm{R}^{2}$ values of 0.9957 and 0.9476 for the same initial concentrations. However, the $95 \%$ prediction bands for both models showed a large uncertainty in the location of future observations. For example, the PFO model fit for the $10 \mathrm{mg} / \mathrm{L}$ experiments predicted a range of 9.6 to $10.8 \mathrm{mg} / \mathrm{L}$ for the initial concentration; this was narrower than the 8.2 to $12.3 \mathrm{mg} / \mathrm{L}$ range predicted by the PSO model. The uncertainty of the future observations increased even further for the $20 \mathrm{mg} / \mathrm{L}$ runs. These extremely large uncertainties makes the application of these kinetic models extremely risky. For the present study, it can generally be concluded that the PFO model best fits the data. However, it is worth noting that the degradation kinetics of methyl orange using various AOPs have resulted in conflicting results, with some authors identifying the reaction as first order [49] and others as second order [50]. 
a)

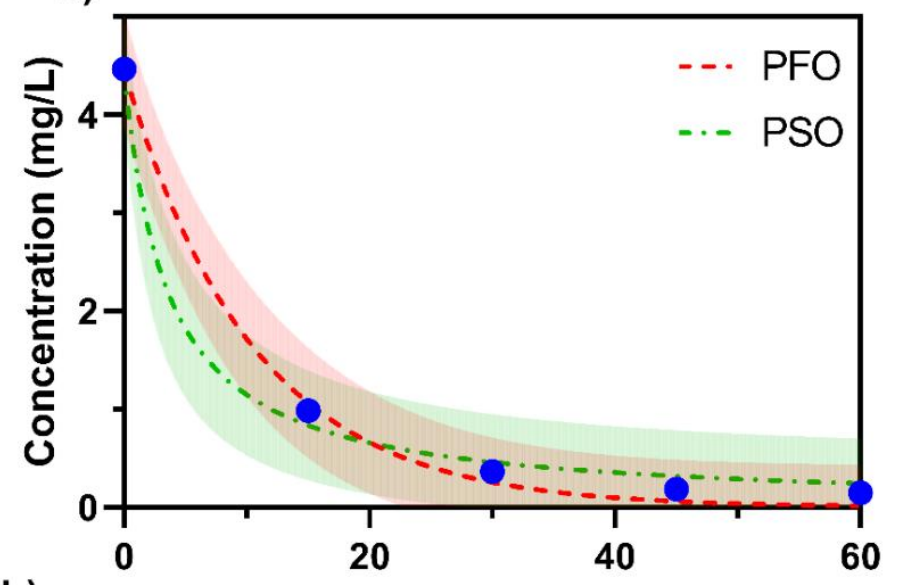

b) Time (min)

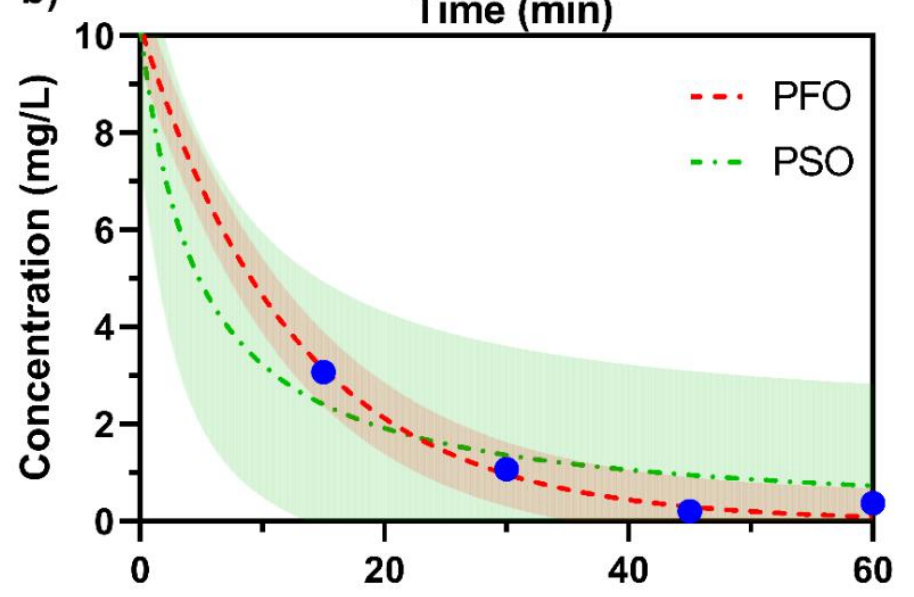

c)

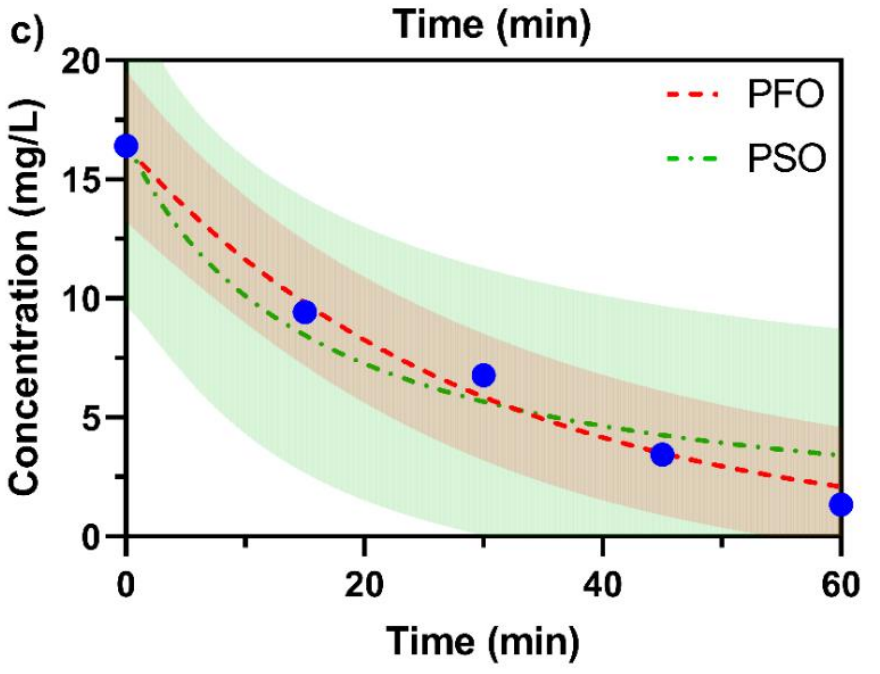

Figure 8. First and second order kinetic modelling at varying initial $\mathrm{MO}$ concentrations: (a) $\mathrm{MO}=5 \mathrm{mg} / \mathrm{L},(\mathbf{b}) \mathrm{MO}=10 \mathrm{mg} / \mathrm{L}$, and (c) $\mathrm{MO}=20 \mathrm{mg} / \mathrm{L}$.

\subsection{TOC Removal}

Near-complete degradation was observed for solutions of the MO concentrations in the range of 5-20 mg/L. However, the extent of the mineralization was not as high, with $37 \%$ TOC removal recorded after $60 \mathrm{~min}$ (Figure 9) for a $10 \mathrm{mg} / \mathrm{L} \mathrm{MO}$ aqueous solution. Fenton-type reactions are renowned for their ability to significantly reduce the total organic carbon (TOC) in both simulated water and environmental samples [19]. However, it is 
acknowledged that the extent of mineralization is largely dependent on the chemical structure of the target compounds, among other factors [51]. Complex aromatic compounds such as $\mathrm{MO}$ are less likely to be directly converted into $\mathrm{CO}_{2}$ and $\mathrm{H}_{2} \mathrm{O}$. Rather they undergo an intricate degradation mechanism, resulting in the formation of an assortment of intermediate organic compounds [52]. It was therefore postulated that similar degradation pathways with intermediate formations occurred in the present investigation.

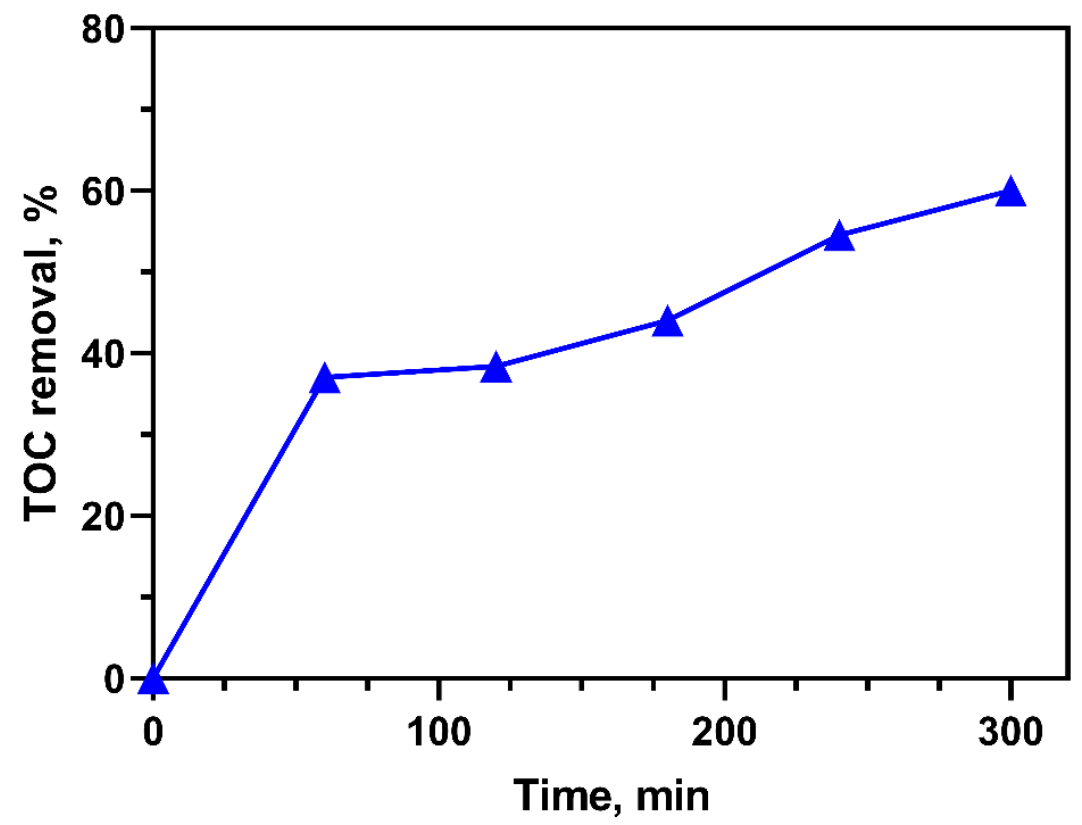

Figure 9. TOC removal over time with an addition of $1.0 \mathrm{mM}$ of $\mathrm{H}_{2} \mathrm{O}_{2}$ every $60 \mathrm{~min}$. Operating conditions: $(\mathrm{MO})=10 \mathrm{mg} / \mathrm{L},\left(\mathrm{H}_{2} \mathrm{O}_{2}\right)=1.0 \mathrm{mM}$, (ilmenite) $=2000 \mathrm{mg} / \mathrm{L}, \mathrm{pH}=2.5$, irradiation $=\mathrm{UVB}$ $(\lambda=310 \mathrm{~nm}-350 \mathrm{~nm})$, and temperature $= \pm 20^{\circ} \mathrm{C}$.

In this study, it was hypothesized that the TOC removal was $\mathrm{H}_{2} \mathrm{O}_{2}$-limited since excess catalyst loadings did not lead to an increase in the rate of reaction. However, the effect of $\mathrm{H}_{2} \mathrm{O}_{2}$ concentration studies revealed that excess amounts negatively affected the reaction due to possible scavenging effects. Taking this into consideration, cyclic tests, which involved adding a fresh dose of $1.0 \mathrm{mM}$ of $\mathrm{H}_{2} \mathrm{O}_{2}$ into the reactor at 60 min intervals, were conducted with the aim of improving the TOC removal efficiency. Some studies have shown that a stepwise addition of $\mathrm{H}_{2} \mathrm{O}_{2}$ improves the efficiency of the Fenton process [53]. Figure 9 shows the evolution of TOC after five cycles. Forty percent of the TOC remained, implying $60 \%$ mineralization.

\section{Materials and Methods}

\subsection{Materials}

Pre-milled $(<54 \mu \mathrm{m})$ ilmenite was supplied by AMIS Matrix Reference Materials (AMIS 0454). The ilmenite was sourced from the Tronox Namakwa Sands Mine at Brandse-Baai in the Northern Cape province of South Africa. Methyl orange powder (85\%), sulphuric acid $\left(\mathrm{H}_{2} \mathrm{SO}_{4} ; 98 \%\right)$, and $\mathrm{H}_{2} \mathrm{O}_{2}(30 \%)$ were all purchased from Sigma Aldrich (St. Louis, MO, USA). All materials were used as received without further processing apart from $\mathrm{H}_{2} \mathrm{SO}_{4}$ which was diluted with ultrapure (de-ionized) water before use. De-ionized water from a Purelab Flex 3 was used in the mixing of all solutions. Three different tubular lamps with different wavelengths were used as sources of irradiation. Table 3 shows the model and corresponding wavelengths of the lamps used. 
Table 3. The model and peak wavelengths of the different lamps used for irradiation.

\begin{tabular}{ccc}
\hline Irradiation Source & Model & Peak Wavelengths (nm) \\
\hline UVA & Philips TL-K 40 W/10 R Actinic BL Reflector & 365 \\
\hline UVB & Exo Terra Reptile UVB 20018 W, 60 cm & $310-350$ \\
\hline Visible & Philips Master Super 80 TL-D 18 W/865 & $440,560,640$ \\
\hline
\end{tabular}

\subsection{Catalyst Characterization}

The catalyst was characterized to elucidate its morphology, mineralogy, elemental composition, and BET surface area. A Zeiss Ultra Plus field emission scanning electron microscope (FE-SEM) was used to capture the SEM/EDS images. XRD spectra were determined using a PANalytical $X^{\prime}$ Pert Pro powder diffractometer in $\theta-\theta$ configuration fitted with an $X^{\prime}$ Celerator detector and variable divergence with Fe-filtered $\mathrm{Co}-\mathrm{K} \alpha$ radiation $(\lambda=1.789 \AA)$-fixed slits. The mineral phases present were confirmed using $X^{\prime}$ Pert Highscore plus software, which indexed the spectra against the ICSD database. The weight fractions of the various phases were estimated using the Rietveld method. The elemental composition of the catalyst was examined using the Thermo Fisher ARL Perform' $X$ Sequential XRF instrument with Uniquant software. Only elements found above the detection limits were reported. A Micrometrics Tristar 3000 BET analyzer was used to determine the BET surface area. All samples were degassed for $24 \mathrm{~h}$ at $150{ }^{\circ} \mathrm{C}$ under a $10^{-5}$ Torr vacuum before analysis.

\subsection{Methods}

All degradation experiments were conducted in a closed container lined with reflective material in a temperature-controlled environment $\left(20^{\circ} \mathrm{C}\right)$. Two magnetic stirrers were placed in the container with a tubular lighting fixture placed directly above the stirrers. In addition, $0.8 \mathrm{~L}$ beakers served as reactors; for every experiment, $400 \mathrm{~mL}$ of methyl orange dye (MO) solution was used. The $\mathrm{pH}$ was adjusted to the desired value using a few drops of concentrated $\mathrm{H}_{2} \mathrm{SO}_{4}$; thereafter, the required amount of the catalyst was added. The MO-catalyst suspension was left to equilibrate in the dark for $30 \mathrm{~min}$ before switching on the light source and adding $\mathrm{H}_{2} \mathrm{O}_{2}$. Several aliquots were taken at predetermined intervals, centrifuged, filtered, and analyzed using a WPA-Lightwave II UV-vis spectrophotometer.

A set of control experiments were conducted to establish the effect of the presence of the catalyst, namely $\mathrm{H}_{2} \mathrm{O}_{2}$ or light alone on the degradation of $\mathrm{MO}$. The following initial conditions were used: $(\mathrm{MO})=10 \mathrm{mg} / \mathrm{L}$, (ilmenite $)=1 \mathrm{~g} / \mathrm{L},\left(\mathrm{H}_{2} \mathrm{O}_{2}\right)=2.5 \mathrm{mM}, \mathrm{pH}=3$, and irradiation $=$ UVB.

The subsequent parameter optimization experiments were conducted following a procedure similar to the one described for the control experiments. However, alterations were made to the parameter being optimized. The initial conditions were used in all experiments unless the optimal condition was determined, in which case the optimal condition was used. The effect of $\mathrm{pH}$ was investigated at $\mathrm{pH}$ values of $2,2.5,3$, and 5 . This was tested in conjunction with four irradiation conditions (dark, UVA, UVB, and visible). Thereafter, the effect of the catalyst loading was tested in a range of $0 \mathrm{mg} / \mathrm{L}$ to $2500 \mathrm{mg} / \mathrm{L}$, followed by the optimization of the effect of the $\mathrm{H}_{2} \mathrm{O}_{2}$ concentration ranging from $0.0 \mathrm{mM}$ to $40.0 \mathrm{mM}$. Once the optimal conditions were determined, methyl orange concentrations were varied to examine the effect of the initial concentration $(5,10$, and $20 \mathrm{mg} / \mathrm{L})$.

In order to establish the dominant reaction mechanism, the concentration of iron in solution was determined at varying $\mathrm{pH}$ and catalyst loadings. The iron concentration was determined using a spectro genesis inductively coupled plasma optical emission spectrometry (ICP-OES). An additional $24 \mathrm{~h}$ leaching tests at $\mathrm{pH} 2.5$ were conducted in order to determine the stability of the catalyst. XRD analysis was conducted on the recovered solid residue. 
The degree of the mineralization of the MO was investigated using a Shimadzu TOC-V wp Total Organic Carbon (TOC) analyzer. Samples were analyzed before reaction and after selected periods thereafter. The extent of the MO degradation and possible formation of organic intermediate products was analyzed using a Nexera LC-40 System coupled to an LCMS-9030 Q-TOF operated in the negative ESI mode. Chromatographic separation was performed using a gradient of the mobile phase $(\mathrm{A})$, water containing $0.1 \%(v / v)$ formic acid, and (B) acetonitrile.

\section{Conclusions}

Naturally occurring South African ilmenite sands were found to be an effective ironbearing catalyst in the chemical wet peroxide oxidation of methyl orange dye in simulated wastewater. Complete decolorization of $\mathrm{MO}$ was observed, leading to unidentified intermediate products. The reaction was highly dependent on the initial $\mathrm{pH}$ of the solution, which in turn influenced the extent of iron leaching. Decolorization occurred via the homogeneous Fenton's reaction mechanism, although less leached iron was required. UVB irradiation improved the rate of reaction by aiding the cycling of Fe (II) and Fe (III) in the aqueous phase. The concentration of $\mathrm{H}_{2} \mathrm{O}_{2}$ was found to play a pivotal role in both the decolorization of $\mathrm{MO}$ and subsequent mineralization of the intermediate products formed.

Supplementary Materials: The following are available online at https:/ /www.mdpi.com/article/10 $.3390 /$ catal11121452/s1. Figure S1: SEM-EDS Micrographs of three different sites ( $a, b$ and $c)$ of the catalyst sample using EDS to determine the elemental composition.

Author Contributions: Conceptualization, A.L.B. and S.M.T.; methodology, A.L.B. and S.M.T.; investigation, A.L.B.; resources, S.M.T.; data curation, A.L.B., J.K.M. and S.M.T.; writing-original draft preparation, A.L.B.; writing-review and editing, A.L.B., J.K.M. and S.M.T.; supervision, S.M.T.; funding acquisition, S.M.T. All authors have read and agreed to the published version of the manuscript.

Funding: This research study was funded by the National Research Foundation (NRF) of South Africa, grant number TTK18024324064, awarded to Shepherd M. Tichapondwa of the University of Pretoria.

Data Availability Statement: Not applicable.

Acknowledgments: The authors would like to thank AMIS Matrix Reference Materials for supplying the ilmenite samples used in this study. They also thank Charl Hertzog and Wiebke Grote from the University of Pretoria for assisting with the ICP and XRD analysis, respectively, as well as Alette Devega for all the technical and logistical support in the lab.

Conflicts of Interest: The authors declare no conflict of interest.

\section{References}

1. Water Research Commission. Parched prospects: The Emerging Water Crisis in South Africa. Water Wheel 2014, $13,42-47$.

2. Oller, I.; Malato, S.; Pérez, J.A.S. Combination of Advanced Oxidation Processes and biological treatments for wastewater decontamination-A review. Sci. Total Environ. 2011, 409, 4141-4166. [CrossRef] [PubMed]

3. Walker, C.H. Polycyclic Aromatic Hydrocarbons. In Organic Pollutants: An Ecotoxicological Perspective, 2nd ed.; CRC Press: Boca Raton, FL, USA, 2009.

4. Hai, F.I. Hybrid Treatment Systems for Dye Wastewater. Crit. Rev. Environ. Sci. Technol. 2007, 37, 315-377. [CrossRef]

5. Qasim, S.R.; Zhu, G. Biological Waste Treatment. In Wastewater Treatment and Reuse: Theory and Design Examples; CRC Press: Boca Raton, FL, USA, 2018.

6. Jelic, A.; Katsou, E.; Malamis, S.; Bolzonella, D.; Fatone, F. Occurrence, Removal, and Fate of PAHs and VOCs in Municipal Wastewater Treatment Plants: A Literature Review. In Wastewater Treatment: Occurrence and Fate of Polycyclic Aromatic Hydrocarbons (PAHs); Forsgren, A.J., Ed.; CRC Press: Boca Raton, FL, USA, 2015.

7. Ankush Mandal, M.K.; Sharma, M.; Khushboo Pandey, S.; Dubey, K.K. Membrane Technologies for the Treatent of Pharmacceutical Industry Wastewater. In Water and Wastewater Treatment Technologies; Bui, X.-T., Chiemchaisri, C., Fujioka, T., Varjani, S., Eds.; Springer: Singapore, 2019.

8. Ameta, S.C.; Ameta, R. Introduction. In Advanced Oxidation Processes for Wastewater Treatment: Emerging Green Chemical Technology, 1st ed.; Ameta, S.C., Ameta, R., Eds.; Academic Press: Cambridge, MA, USA, 2018.

9. Ameta, R.; Chohadia, A.K.; Jain, A.; Punjabi, P.B. Fenton and Photo-Fenton Processes. In Advanced Oxidation Processes for Wastewater Treatment; Academic Press: Cambridge, MA, USA, 2018. 
10. Zhu, Y.; Zhu, R.; Xi, Y.; Zhu, J.; Zhu, G.; He, H. Strategies for enhancing the heterogeneous Fenton catalytic reactivity: A review. Appl. Catal. B Environ. 2019, 255, 1-16. [CrossRef]

11. Soon, A.N.; JHameed, B.H. Heterogeneous catalytic treatment of synthetic dyes in aqueous media using Fenton and photo-assisted Fenton process. Desalination 2011, 269, 1-16. [CrossRef]

12. Rezaei, F; Vione, D. Effect of $\mathrm{pH}$ on zero valent iron performance in heterogeneous fenton anf fenton-like processes: A review. Molecules 2018, 23, 3127. [CrossRef] [PubMed]

13. Minella, M.; Bertinetti, S.; Hanna, K.; Minero, C.; Vione, D. Degradation of ibuprofen and phenol with a Fenton-like process triggered by zero-valent iron (ZVI-Fenton). Environ. Res. 2019, 179, 108750. [CrossRef]

14. Jack, R.S.; Ayoko, G.A.; Adebajo, M.O.; Frost, R.L. A review of iron species for visible-light photocatalytic water purification. Environ. Sci. Pollut. Res. 2015, 22, 7439-7449. [CrossRef] [PubMed]

15. Vorontsov, A.V. Advancing Fenton and photo-Fenton water treatment through the catalyst design. J. Hazard. Mater. 2019, 372, 103-112. [CrossRef]

16. Tokumura, M.; Morito, R.; Hatayama, R.; Kawase, Y. Iron redox cycling in hydroxyl radical generation during the photo-Fenton oxidative degradation: Dynamic change of hydroxyl radical concentration. Appl. Catal. B Environ. 2011, 106, 565-576. [CrossRef]

17. Tehrani-Bagha, A.R.; Balchi, T. Catalytic Wet Peroxide Oxidation. In Advanced Oxidation Processes for Wastewater Treament; Ameta, R., Ameta, S.C., Eds.; Elsevier: Amsterdam, The Netherlands, 2018.

18. Rueda Márquez, J.J.; Levchuk, I.; Sillanpää, M. Application of catalytic wet peroxide oxidation for industrial and urban wastewater treatment: A review. Catalysts 2018, 8, 673. [CrossRef]

19. Wang, N.; Zheng, T.; Zhang, G.; Wang, P. A review on Fenton-like processes for organic wastewater treatment. J. Environ. Chem. Eng. 2016, 4, 762-787. [CrossRef]

20. Mak, C.H.; Han, X.; Du, M.; Kai, J.-J.; Tsang, K.F.; Jia, G.; Cheng, K.-C.; Shen, H.-H.; Hsu, H.-Y. Heterogenization of homogeneous photocatalysts utilizing synthetic and natural support materials. J. Mater. Chem. A 2021, 9, 4454-4504. [CrossRef]

21. García-Muñoz, P.; Pliego, G.; Zazo, J.A.; Bahamonde, A.; Casas, J.A. Ilmenite $\left(\mathrm{FeTiO}_{3}\right)$ as low cost catalyst for advanced oxidation processes. J. Environ. Chem. Eng. 2016, 4, 542-548. [CrossRef]

22. Munoz, M.; Domínguez, P.; De Pedro, Z.M.; Casas, J.A. Naturally occurring iron minerals as inexpensive catalysts for CWPO. Appl. Catal. B Environ. 2017, 203, 166-173. [CrossRef]

23. Lu, M.-C.; Chen, J.-N.; Huang, H.-H. Role of Goethite dissolution in the oxidation of 2-chlorophenol with hydrogen peroxide. Chemosphere 2002, 46, 131-136. [CrossRef]

24. García-Muñoz, P.; Pliego, G.; Zazo, J.A.; Munoz, M.; De Pedro, Z.M.; Bahamonde, A.; Casas, J.A. Treatment of hospital wastewater through the CWPO-Photoassisted process catalyzed by ilmenite. J. Environ. Chem. Eng. 2017, 5, 4337-4343. [CrossRef]

25. García-Muñoz, P.; Pliego, G.; Bahamonde, A.; Casas, J.A. Sulfonamides photoassisted oxidation treatments catalyzed by ilmenite. Chemosphere 2017, 180, 523-530. [CrossRef] [PubMed]

26. Pataquiva-Mateus, A.Y.; Zea, H.R.; Ramirez, J.H. Degradation of Orange II by Fenton reaction using ilmenite as catalyst. Environ. Sci. Pollut. Res. 2017, 24, 6187-6194. [CrossRef] [PubMed]

27. Tichapondwa, S.M.; Newman, J.P.; Kubheka, O. Effect of $\mathrm{TiO}_{2}$ phase on the photocatalytic degradation of methylene blue dye. Phys. Chem. Earth 2020, 118-119, 102900. [CrossRef]

28. Canas-Martinez, D.M.; Gauthier, G.H.; Pedraza-Avella, J.A. Photo-oxidative and photo-reductive capabilities of ilmenite-rich black sand concentrates using methyl orange as a probe molecule. Photochem. Photobiol. Sci. 2019. [CrossRef] [PubMed]

29. Silveira, J.E.; Paz, W.S.; García-Muñoz, P.; Zazo, J.A.; Casas, J.A. UV-LED/ilmenite/persulfate for azo dye mineralization: The role ofsulfate in the catalyst deactivation. Appl. Catal. B Environ. 2017, 219, 314-321. [CrossRef]

30. Kuo, W.G. Decolorizing Dye Wastewater with Fenton's Reagent. Water Res. 1992, 26, 881-886. [CrossRef]

31. Voelker, B.M.; Morel, F.M.M.; Sulzerger, B. Iron Redox Cycling in Surface Waters: Effect of Humic Substances and Light. Environ. Sci. Technol. 1997, 31, 1004-1011. [CrossRef]

32. Rijkenberg, M.J.A.; Gerringe, L.J.A.; Neale, P.J.; Timmermans, K.R.; Buma, A.G.J.; De Baar, H.J.W. UVA viability overrules UVB ozone depletion effects on the photoreduction of iron in the Southern Ocean. Geophys. Res. Lett. 2004, 31, 8. [CrossRef]

33. Rijkenberg, M.J.A.; Fischer, A.C.; Kroon, J.J.; Gerringe, L.J.A.; Timmermans, K.R.; Wolterbeek, H.T.; de Baar, H.J.W. The influence of UV irradiation on the photoreduction of iron in the Southern Ocean. Mar. Chem. 2005, 93, 119-129. [CrossRef]

34. Lueder, U.; Jorgensen, B.B.; Kappler, A.; Schmidt, C. Photochemistry of iron in aquatic environments. Environ. Sci. Process. Impacts 2020, 22, 12-24. [CrossRef]

35. Eskandarian, M.R.; Choi, H.; Fazli, M.; Rasoulifard, M.H. Effect of UV-LED wavelength on direct photolytic and TiO 2 photocatalytic degradation of emerging contaminants in water. Chem. Eng. J. 2016, 300, 414-422. [CrossRef]

36. Nidheesh, P.V. Heterogeneous Fenton catalysts for the abatement of organic pollutants from aqueous solution: A review. R. Soc. Chem. 2015, 5, 40552-40577. [CrossRef]

37. Pignatello, J.J.; Oliveros, E.; MacKay, A. Advanced Oxidation Processes for Organic Contaminant Destruction Based on the Fenton Reaction and Related Chemistry. Crit. Rev. Environ. Sci. Technol. 2006, 36, 1-84. [CrossRef]

38. Beverskog, B.; Puigdomenech, I. Revised pourbaix diagrams for iron at 25-300 ${ }^{\circ}$ C. Corros. Sci. 1996, 38, 2121-2135. [CrossRef]

39. Salgado, P.; Melin, V.; Contreras, D.; Moreno, Y.; Mansilla, H. Fenton Reaction Driven by Iron Ligands. J. Chil. Chem. Soc. 2013, 58, 2096-2101. [CrossRef] 
40. García-Muñoz, P.; Pliego, G.; Antonio Zazo, J.; Casas, J.A. Photocatalytic wet peroxide oxidation process at circumneutral pH using ilmenite as catalyst. J. Environ. Chem. Eng. 2018, 6, 7312-7317. [CrossRef]

41. Butt, A.L.; Tichapondwa, S.M. Catalytic Wet Peroxide Oxidation of Methyl Orange using Naturally-Occurring South African Ilmenite as a Catalyst. Chem. Eng. Trans. 2020, 81, 367-371.

42. Dai, K.; Chen, H.; Peng, T.; Ke, D.; Yi, H. Photocatalytic degradation of methyl orange in aqueous suspension of mesoporous titania nanoparticles. Chemosphere 2007, 69, 1361-1367. [CrossRef] [PubMed]

43. Cohen, M.; Ferroudj, N.; Combes, A.; Pichon, V.; Abramson, S. Tracking the degradation pathway of three model aqueous pollutants in a heterogeneous Fenton process. J. Environ. Chem. Eng. 2019, 7. [CrossRef]

44. Jiang, C.; Pang, S.; Ouyang, F.; Ma, J.; Jiang, J. A new insight into Fenton and Fenton-like processes for water treatment. J. Hazard. Mater. 2010, 174, 813-817. [CrossRef] [PubMed]

45. Wang, J.; Wang, S. Reactive species in advanced oxidation processes: Formation, identification and reaction mechanism. Chem. Eng. J. 2020, 401, 1-19. [CrossRef]

46. Zhang, T.; Zhu, H.; Croue, J.-P. Production of Sulfate Radical from Peroxymonosulfate Induced by a Magnetically Separable $\mathrm{CuFe}_{2} \mathrm{O}_{4}$ Spinel in Water: Efficiency, Stability, and Mechanism. Environ. Sci. Technol. 2013, 47, 2784-2791. [CrossRef] [PubMed]

47. Maduna, K.; Kumar, N.; Aho, A.; Wärnå, J.; Zrnčević, S.; Murzin, D.Y. Kinetics of Catalytic Wet Peroxide Oxidation of Phenolics in Olive Oil Mill Wastewaters over Copper Catalysts. ACS Omega 2018, 3, 7247-7260. [CrossRef]

48. Hyndman, R.J.; Athanasopoulos, G. Forecasting: Principles and Practice; OTexts: Melbourne, Australia, 2018.

49. García-Muñoz, P.; Pliego, G.; Zazo, J.A.; Barbero, B.; Bahamonde, A.; Casas, J.A. Modified ilmenite as catalyst for CWPOPhotoassisted process under LED light. Chem. Eng. J. 2016. [CrossRef]

50. Youssef, N.A.; Shaban, S.A.; Ibrahim, F.A.; Mahmoud, A.S. Degradation of methyl orange using Fenton catalytic reaction. Egypt. J. Pet. 2016, 25, 317-321. [CrossRef]

51. Ganzenko, O.; Trellu, C.; Oturan, N.; Huguenot, D.; Péchaud, Y.; van Hullebusch, E.D.; Oturan, M.A. Electro-Fenton treatment of a complex pharmaceutical mixture: Mineralization efficiency and biodegradability enhancement. Chemosphere 2020, 253, 126659. [CrossRef] [PubMed]

52. Konstantinou, I.K.; Albanis, T.A. TiO $\mathrm{T}_{2}$-assisted photocatalytic degradation of azo dyes in aqueous solution: Kinetic and mechanistic investigations: A review. Appl. Catal. B Environ. 2004, 49, 1-14. [CrossRef]

53. Zhang, H.; Wu, X.; Li, X. Oxidation and coagulation removal of COD from landfil leachate by Fered-Fenton process. Chem. Eng. J. 2012, 210, 188-194. [CrossRef] 